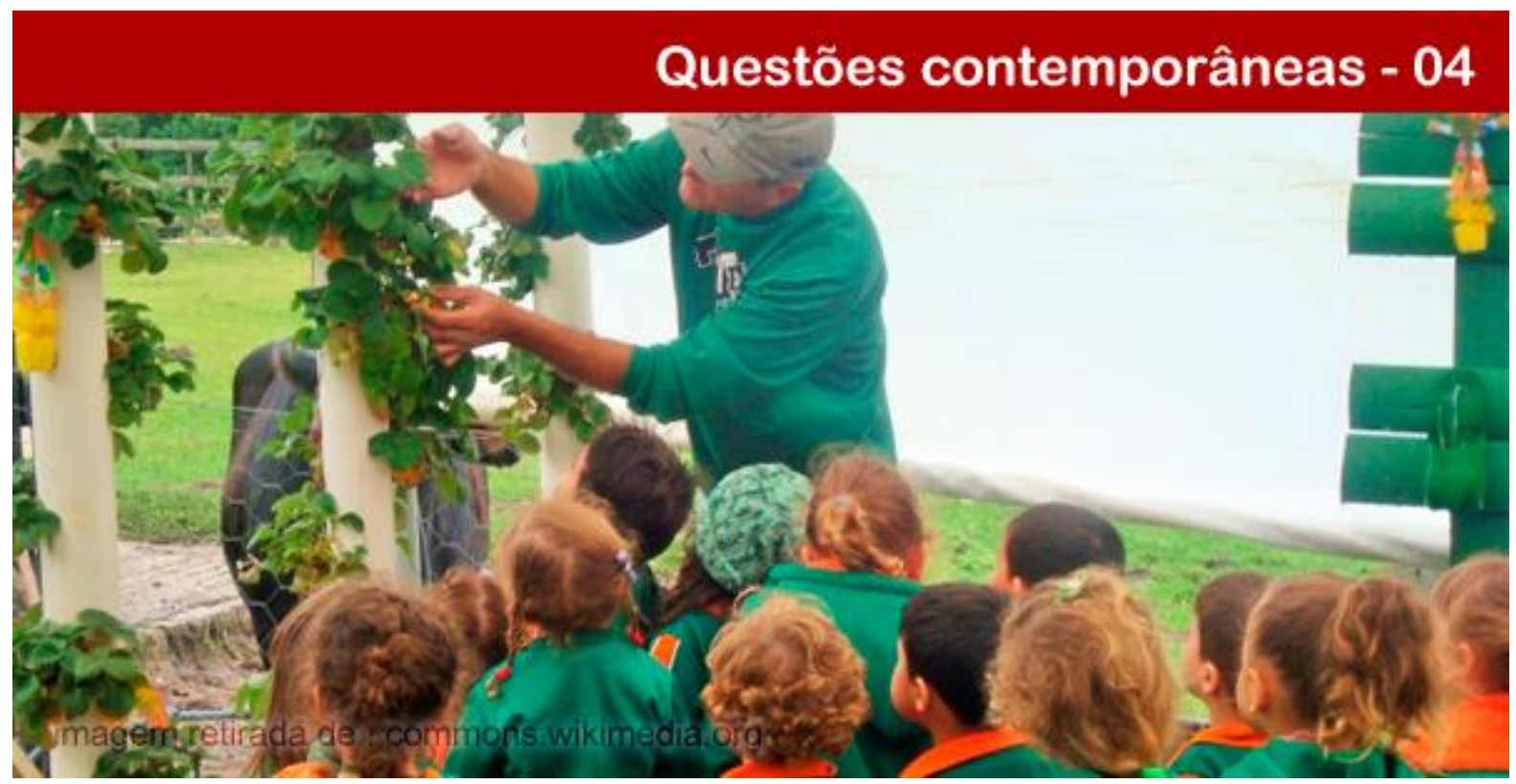

\title{
A EDUCAÇÃO DO CAMPO ENQUANTO UM HORIZONTE PARA O DESENVOLVIMENTO DE UM MODELO DE ECONOMIA
}

\section{Edivaldo José Bortoleto}

Doutor em Comunicação e Semiótica pela Pontifícia Universidade Católica de São Paulo (PUC-SP) e Doutor em Educação pela Universidade Metodista de Piracicaba (UNIMEP). Professor pesquisador do Programa de Pós-graduação em Educação da Universidade Comunitária da Região de Chapecó (Unochapecó). E-mail: ejbortol@unochapeco.edu.br.

\section{Luci Teresinha Marchiori dos Santos Bernardi}

Doutora em Educação Científica e Tecnológica pela Universidade Federal de Santa Catarina (UFSC). Professora pesquisadora do Programa de Pós-graduação em Educação da Universidade Comunitária da Região de Chapecó (Unochapecó). E-mail: lucib@unochapeco.edu.br.

\section{Nadia Cristina Picinini Pelinson}

Mestre em Educação pela Universidade Comunitária da Região de Chapecó (Unochapecó). Professora da Educação Básica da Rede Estadual de Ensino de Santa Catarina e do Ensino Superior. E-mail: ndpelinson@hotmail.com.

Resumo: A reflexão proposta neste artigo coloca em tela a Educação do Campo e as condições educacionais que possibilitem o desenvolvimento de um modo de vida dos camponeses em um espaço onde a mercadoria seja produto de relações sociais e não a produtora, que valorize o homem e o seu trabalho, que supere a competitividade com vistas na comunitariedade. Assim, quer se pensar uma Educação do Campo enquanto um horizonte para o desenvolvimento de um modelo de economia que está em consonância histórica, epistemológica e lógica com a Pedagogia da Alternância: a Economia de Comunhão.

Palavras-chave: Educação do campo. Pedagogia da alternância. Economia de comunhão.

\section{THE RURAL EDUCATION AS HORIZONTAL FOR THE DEVELOPMENT OF AN ECONOMIC MODEL}

Abstract: The reflection proposed in this paper put on stage the Rural Education and the educational conditions that makes possible the peasants way of life development in one space where the goods are one product of social relations and not the producer, that values the man and his work, that exceeds the competitiveness looking for

\section{POLÊM!CA | LABORE (3)}

Polêmica - Revista Eletrônica da Uerj - Rua São Francisco Xavier, 524, $1^{\circ}$ andar bloco D, sl.1001 • Tels.: +55 21 2334-4088 / 4087 • http://www.e-publicacoes.uerj.br/index.php/polemica/index http://www.labore.uerj.br • laboreuerj@yahoo.com.br 
the community. Thus, it want to think in Rural Education as one horizon for the development of one economic model that is aligned historical, epistemological and logical with Pedagogy of Alternance and the Economy of Communion.

Keywords: Rural education. Pedagogy of alternance. Economy of communion.

\section{Introdução}

A questão do campo é um tema essencialmente imbricado com o problema da terra. Refletir tal temática supõe reconhecer um conjunto de outros tantos pontos fundamentais que a cercam tensionalmente, quais sejam: a população campesina, a população ribeirinha, a população quilombola, a população indígena, a população caiçara, a população extrativista, a população de pesqueiros e, ao mesmo tempo, a população citadina, pois o fenômeno do êxodo rural é uma realidade que se impõe e sem o qual não se compreende, por exemplo, o fenômeno das cidades, principalmente das metrópoles, juntamente com as questões do urbanismo, da moradia, da qualidade de vida, da violência, etc. Enfim, o problema da densidade demográfica hoje no planeta, no contexto das diversas e diferentes culturas, principalmente no Brasil em sua grande extensão e, de resto, em toda extensão da América Latina Caribenha, é uma questão decisiva e necessária a ser enfrentada. Não se pode pensar o campo sem a cidade e, vice-versa, não se pode pensar a cidade sem o campo.

Desta maneira, o problema do campo e da educação do campo em suas dimensões mais particulares e singulares ganham sentido no horizonte maior da densidade demográfica, portanto, mais universal, que não pode ser perdido de vista. Inevitavelmente, enfrentar a questão da densidade demográfica supõe o auxílio de ciências tais como, a Economia, a Sociologia, a Geografia, a Biologia, a Ecologia, etc., isto porque o olhar e o escutar refletidos da densidade demográfica com todas as suas questões nela inerentes só podem se dar, tão somente, de maneira interdisciplinar.

Assim, sem perder de mira tais questões que se configuram em âmbito singular, particular e universal e, os olhares e os ouvires interdisciplinares, esta reflexão quer se mover no âmbito da e na problemática do campo e da educação, mais precisamente da educação do campo. Mas, falar em educação do campo é já entrar em um campo eminentemente polissêmico, pois muitas são as suas compreensões e formulações ${ }^{1}$. No caso específico desta

\footnotetext{
${ }^{1}$ Caldart (2012) no verbete Educação do Campo demonstra o surgimento do conceito a partir de experiências significativas características da prática social de onde tal conceito emerge. Segundo a autora tal conceito pode ser datado. "Nasceu primeiro - diz a autora - como Educação Básica do Campo no contexto de preparação da I Conferência Nacional por uma Educação Básica do Campo, realizada em Luziânia, Goiás, de 27 a 30 de julho de
}

\section{POLÊM!CA $\mid$ LABORE}


reflexão, quer se tomar, no âmbito da Educação do Campo, a Pedagogia da Alternância, a partir da aproximação de elementos teóricos advindos de uma educação que não se circunscreve na educação formal - a Pedagogia da Alternância - das escolas nas cidades por um lado e, por outro, de outras formulações teóricas e, ao mesmo tempo práticas, de modelos de teorias econômicas que não se fiam pelo modelo econômico dominante e hegemônico constitutivo da lógica do capital - a Economia de Comunhão. Desta maneira, é desde o horizonte da Educação do Campo que se quer mirar para a possibilidade de desenvolvimento de um modelo de economia em consonância com a Pedagogia da Alternância, no caso, a Economia de Comunhão, sem, no entanto, se fechar para outras possibilidades de modelos econômicos, como, por exemplo, a Economia Solidária.

Portanto, este artigo comporta três momentos, a partir de uma revisão bibliográfica deste campo de estudo. Um primeiro momento no qual se discute a educação do campo nas últimas décadas. Um segundo momento em que se discute a Pedagogia da Alternância e como ela ganha capilaridade, principalmente no Brasil. E por fim, um terceiro momento, a Economia de Comunhão enquanto uma formulação de um modelo econômico que está em consonância histórica, epistemológica e lógica com a Pedagogia da Alternância.

\section{Educação do Campo: o movimento nas últimas décadas}

A população do campo, assim como todas as questões voltadas ao meio rural, por muito tempo foi deixada de lado nas políticas públicas. Pesquisas educacionais, conforme Arroyo et al (2011), mostram essa trajetória histórica de abandono em relação ao homem do campo, considerando que somente $2 \%$ desse material abrangem tal temática. Os autores inferem que o movimento Por uma Educação do Campo nasceu para denunciar esse silenciamento e esquecimento, tanto por órgãos governamentais como por pesquisadores das questões sociais e educacionais.

Ghedin (2012) afirma que as lutas por uma educação do campo ganham um novo cenário a partir de 1990. Camponeses e os movimentos sociais reuniram-se para discutir,

1988. Passou a ser chamada Educação do Campo a partir das discussões do Seminário Nacional realizado em Brasília de 26 a 29 de novembro de 2002, decisão posteriormente reafirmada nos debates da II Conferência Nacional, realizada em julho de 2004". Tal conceito subsumido pelo MST no Primeiro Enera - I Encontro Nacional dos Educadores e Educadoras da Reforma Agrária - apresenta-se como questão desafiadora que se seguirá no seio do Pronera - Programa Nacional de Educação na Reforma Agrária. Conferir as páginas do verbete Educação do Campo. (CALDART, 2012, p. 257-265).

\section{POLÊM!CA $\mid$ LABORE}

Polêmica - Revista Eletrônica da Uerj - Rua São Francisco Xavier, 524, $1^{\circ}$ andar

bloco D, sl.1001 • Tels.: +55 21 2334-4088 / 4087 • http://www.e-publicacoes.uerj.br/index.php/polemica/index http://www.labore.uerj.br • laboreuerj@yahoo.com.br 
propor e reivindicar do poder público uma política de educação para os povos que vivem no e do campo. Mas qual seria a diferença entre educação do campo e educação rural, em meio a esse cenário de lutas por uma Educação do Campo com qualidade?

Conforme Caldart:

A educação do campo nomeia um fenômeno de realidade brasileira atual, protagonizado pelos trabalhadores do campo e suas organizações, que visa incidir sobre a política da educação desde os interesses sociais das comunidades camponesas. Os objetivos e sujeitos a remeterem às questões do trabalho, da cultura, do conhecimento e das lutas sociais dos camponeses e ao debate (de classes) entre projetos de campo e entre lógicas de agricultura que têm implicações no projeto de país e de sociedade e nas concepções de políticas públicas, de educação e de formação humana. (CALDART, 2012, p. 259).

A Educação do Campo procura construir um terreno sólido, a partir de um projeto político pedagógico construído pelos próprios sujeitos. Nesse âmbito, a escola almeja, além de formar alunos, uma educação que contribua com a vida do aluno no meio em que se insere fora do espaço escolar.

Em relação à Educação Rural, Caldart explica:

Trata-se dos camponeses, ou seja, daqueles que residem e trabalham nas zonas rurais e recebem o menor rendimento pelo seu trabalho. Para este sujeito, quando existe uma escola na área em que vivem, é oferecida uma educação da mesma modalidade da que é oferecida às populações que residem e trabalham nas áreas urbanas, não havendo, de acordo com os autores, nenhuma tentativa de adequar a escola rural às características dos camponeses ou dos seus filhos, quando estes a frequentam. (CALDART, 2012, p. 295).

Logo, há uma significativa diferença entre as duas concepções de escola. A primeira tende a potencializar seus alunos, a partir do meio em que vivem, enquanto a segunda apenas contribui para reproduzir aos alunos sem a crítica devida o conjunto dos saberes, sem levar em consideração o espaço onde vivem e suas peculiaridades.

A proposta de Educação do Campo, conforme Ghedin (2012), veio sendo definida por parte dos movimentos sociais, em especial o Movimento dos Sem Terra (MST). Este, desde 1984, vem se preocupando em como e o que fazer com as crianças assentadas para garantirlhes a educação adequada à realidade nos assentamentos. A partir dessas indagações, surgiram as primeiras discussões a respeito de uma Educação do Campo: “[...] a Educação do Campo nasceu também como crítica à Educação centrada em si mesma ou em abstrato; seus sujeitos lutaram desde o começo para que o debate pedagógico se colasse a sua realidade, de relações

\section{POLÊM!CA $\mid$ LABORE}

Polêmica - Revista Eletrônica da Uerj - Rua São Francisco Xavier, 524, $1^{\circ}$ andar

bloco D, sl.1001 • Tels.: +55 21 2334-4088 / 4087 • http://www.e-publicacoes.uerj.br/index.php/polemica/index

http://www.labore.uerj.br • laboreuerj@yahoo.com.br 
sociais concretas de vida acontecendo em sua necessária complexidade" (CALDART, 2007 apud GHEDIN, 2012, p. 201).

De acordo com Ghedin (2012), a Educação do Campo foi inspirada a partir de um pensamento educacional socialista, que colidiu com os ideais do regime militar em 1964, sendo retomada com os movimentos sociais na década de 1990, período em que várias ações educativas foram desenvolvidas em prol da população do campo.

Assim, a Educação do Campo e as escolas do/no campo nasceram por meio das lutas e reivindicações dos camponeses e movimentos sociais preocupados em denunciar o silenciamento e esquecimento por parte dos órgãos governamentais, núcleos de financiamentos, estímulos à pesquisa, organizações sociais e educacionais em relação ao campo. Ao fazer uma retrospectiva, se observa que há aproximadamente 20 anos a sociedade brasileira começou a despertar e perceber as reivindicações do campo, a partir dos movimentos dos próprios sujeitos envolvidos, que produziram uma dinâmica social e cultural, que interroga a educação e a escola, revertendo, aos poucos, o silenciamento instituído historicamente.

Conforme Arroyo et al (2011, p. 9): “A Educação do Campo não fica apenas na denúncia do silenciamento, ela busca o que há de mais perverso nesse esquecimento: o direito à educação que vem sendo negado à população trabalhadora do campo". Assim, pensar uma Educação do Campo significa ouvir e entender a cultura, a dinâmica social e educativa dos diferentes grupos que formam o povo do campo.

Os movimentos docentes e pedagógicos progressistas, segundo Arroyo et al (2011), nos anos de 1980, foram responsáveis e protagonistas dos avanços da educação como direito. Educação, direito de todo cidadão, dever do Estado; este foi o clamor ouvido nas praças e ruas em todas as cidades. Jovens, crianças, homens e mulheres do campo participaram desse movimento, fazendo um contraponto ao esquecimento do grupo quando da definição das políticas governamentais:

As políticas educacionais no Brasil padecem de uma indefinição de rumos. E as políticas para o campo ainda mais. As escolas do meio rural passaram a ser tratada como resíduos do sistema educacional brasileiro e, consequentemente, à população do campo foi negado o acesso aos avanços obtidos nas últimas décadas, no reconhecimento e garantia do direito à educação básica (ARROYO et al, 2011, p. 10).

\section{POLÊM!CA $\mid$ LABORE}


Nos dias atuais, a Educação do Campo constitui-se como uma política pública, nos movimentos sociais, nas universidades, nas escolas entre outros e, a cada ano, avança nas Secretarias Municipais de Educação, porém, a passos lentos. Segundo Fernandes et al:

Estima-se que mais de $50 \%$ da população brasileira da faixa etária própria ao Ensino Médio (15 aos 17 anos) esteja fora da escola. 54,3\% das matrículas no ensino médio estão na faixa etária acima de 17 anos. Por sua vez, a matrícula no meio rural representa, desde 1991, apenas $1,1 \%$ do total destas matrículas, e o número de escolas não passa de 3,2\%. (FERNANDES et al, 2011, p. 36).

Os Princípios da Educação do Campo, regulamentados nas Diretrizes Operacionais para Educação Básica nas Escolas do Campo (artigo 2º §único), estabelecem que:

[...] a educação do campo é uma concepção político-pedagógica voltada para dinamizar a ligação dos seres humanos com a produção das condições de existência social, na relação com a terra e o meio ambiente, incorporando os povos e o espaço da floresta, da pecuária, das minas, da agricultura, os pesqueiros, caiçaras, ribeirinhos e extrativistas (GHEDIN, 2012, p. 215).

Fernandes (2012) faz uma reflexão quanto aos territórios da Educação do Campo, pois desafiam a construção de condições educacionais que possam garantir o desenvolvimento de um modo de vida em que a família, a terra, o alimento, a comunidade, as pessoas e a escola estejam acima de qualquer mercadoria. Ou seja:

A mercadoria não vem em primeiro lugar, como território de uma educação capitalizada. $\mathrm{O}$ espaço da vida é que nos move à solidariedade, às parcerias, ao companheirismo, ao comunitário e ao cooperativismo. A mercadoria será produto dessas relações, mas jamais será produtora de relações sociais nos Territórios de Educação do Campo. (FERNANDES, 2012, p. 15).

No âmbito das escolas do campo, o MST procurou inspirar-se em um modelo de pedagogia no qual o desejo é não cortar raízes, sendo uma das vertentes denominada Pedagogia da Alternância. A mesma busca integrar a escola com a família e a comunidade do aluno, permitindo troca de conhecimentos e fortalecimento dos laços familiares e do vínculo dos educandos com os assentamentos, o MST e a terra. Quanto ao modelo econômico assumido pelo MST, a Economia Solidária, em bases epistemológicas e lógicas advindas do campo do pensamento de Karl Marx e Friedrich Engels, vai sendo aproximada à maneira

\section{POLÊM!CA $\mid$ LABORE}

Polêmica - Revista Eletrônica da Uerj - Rua São Francisco Xavier, 524, $1^{\circ}$ andar

bloco D, sl.1001 • Tels.: +55 21 2334-4088 / 4087 • http://www.e-publicacoes.uerj.br/index.php/polemica/index

http://www.labore.uerj.br • laboreuerj@yahoo.com.br 
como o MST formula a Pedagogia da Alternância ${ }^{2}$. À frente, esta questão será retomada quando da discussão do modelo econômico.

\title{
A apropriação da Pedagogia da Alternância e suas contribuições na vida dos jovens campesinos
}

Para ampliar as reflexões sobre o tema aqui proposto, Nosella (2012), apresenta a primeira Maison Familiale Rurale que surge na França, em 1935. A história das EscolasFamília é, antes de tudo, a ideia de um homem, filho de camponês, que por toda vida se comprometeu com o povo do meio rural. Homem que viveu e compartilhou a vida, sentiu as injustiças e pressões com esse povo, o Padre Abbé Granereau ${ }^{3}$.

A ideia de Granereau surge de sua preocupação desde a juventude, ao observar o desinteresse tanto do Estado quanto da Igreja frente aos problemas do homem do campo.

\begin{abstract}
O Estado, através de seus professores (as) do primário, salvo algumas maravilhas e exceções, não sabia mesmo o que dizer aos agricultores a não ser o seguinte: seu filho é inteligente; não pode ser deixado na roça [...] é preciso encaminhá-lo nos estudos [...] vencerá na vida melhor que seu pai [...] conseguirá uma boa posição social. (NOSELLA, 2012, p. 46).
\end{abstract}

Dessa forma, os pais acreditavam que os filhos somente iriam "ser alguém na vida" se saíssem do meio rural. Desacreditados na vida do campo, era nos centros urbanos que a sabedoria e o sucesso poderiam ser almejados e conquistados pelos mais jovens. Assim, fica a terra, o campo na dependência dessa conquista.

Conforme Nosella (2012), a Igreja estava preocupada com a educação de todas as pessoas, sem considerar as especificidades do homem do campo. Aqui vale, porém, um parêntese: esta Igreja de que se está falando é a do século XVIII e XIX, imersa nas grandes questões sociais advindas da Revolução Industrial e da Revolução Francesa, realidades muito mais marcantes no âmbito da cidade do que no campo. De um modo ou de outro ela tinha que se posicionar com o seu pensamento social frente a outros horizontes que iam-se desenhando como o Socialismo, o Comunismo e o Anarquismo. Com sua matriz renascentista, inspirada em um modelo de humanismo clássico, sem perder suas raízes patrístico-escolástica vindas dos Padres da Igreja dos primeiros séculos do Cristianismo e da Escolástica Medieval, bem como da Segunda-Escolástica quando da emergência da modernidade, começa a formular um

${ }^{2}$ Conferir em Löwy (1999) o texto A Luta pela Terra no Brasil de João Pedro Stédile e Frei Sérgio, p. 508-513. 3 Conforme Nosella (2012), Abbé Granereau nasceu em 1885, na França.

\section{POLÊM!CA $\mid$ LABORE}


pensamento social para responder às mudanças sociais que vinham ocorrendo na Europa, principalmente.

Dentre os inúmeros problemas, o jovem padre francês se deparava, então, com um Estado desinteressado com os problemas do campo e uma Igreja voltada ao homem do campo - pois como já sinalizado, as questões e problemas das cidades se impunham -, porém, sem nenhuma alternativa educacional capaz de responder aos problemas desse povo. Assim, toma para si o desafio de pensar alternativas para a educação do homem do campo. Em 1911, ele fundou um Sindicato Rural para ajudar os camponeses a superar o isolamento e, em 1914, a partir deste, concluiu que o problema agrícola era um problema de educação, ou seja, era preciso pensar uma formação capaz de preparar pequenas empresas rurais. Envolvido por esse movimento, em 1930, o Padre sai de uma paróquia urbana e se desloca para uma paróquia rural de Serignac-Péboudou. Foi nesse local que, em 21 de Novembro de 1935, quatro jovens procuraram a paróquia e ali constituiu-se a Primeira Maison Familiale Rurale. Mas como fazer para reunir os jovens de toda paróquia se os mesmos precisavam ajudar seus pais na lavoura?

A partir dessa indagação, o padre começou por organizar os jovens em pequenos grupos e, junto com os agricultores, concluiu que os mesmos iriam se encontrar uma vez por mês, em tempo integral, para depois, retornarem para suas propriedades. Mais adiante, nasceu a ideia da alternância, na qual os jovens permaneciam uma semana na escola da casa do Padre e outra na "escola da vida". Desse movimento surge o que se denomina hoje de Pedagogia da Alternância.

A Pedagogia da Alternância, conforme Gimonet (2007), tem por finalidade abrir caminhos que levam o agricultor, sua família e a comunidade a desenvolver e criar formas alternativas de produção de conhecimento que vão além dos muros da escola e dos livros didáticos, buscar alternativas de garantir trabalho, produção e renda na propriedade, como forma de estimular a permanência dos jovens e sucessão no meio rural. Para Queiroz et al:

O processo de ensino-aprendizagem proposto pela Pedagogia da Alternância possibilita aos alunos vivenciarem momentos na escola, na família e na comunidade. A aquisição do conhecimento se dá de forma construtiva e participativa, envolvendo vários atores: alunos, pais e monitores/professores. (QUEIROZ et al, 2006, p. 60).

O movimento que emerge na Pedagogia da Alternância tem um papel importante na formação dos jovens campesinos; sua articulação de ensino e aprendizagem é descrita por

\section{POLÊM!CA $\mid$ LABORE}

Polêmica - Revista Eletrônica da Uerj - Rua São Francisco Xavier, 524, $1^{\circ}$ andar

bloco D, sl.1001 • Tels.: +55 21 2334-4088 / 4087 • http://www.e-publicacoes.uerj.br/index.php/polemica/index

http://www.labore.uerj.br • laboreuerj@yahoo.com.br 
quatro pilares essenciais que compreendem quatro momentos significativos, quais sejam: a formação integral, o desenvolvimento do meio, a alternância e a associação local.

A formação integral traz consigo a desenvolvimento do meio, associando-se ao local e ao mundo do trabalho, proporcionando aos jovens uma formação de qualidade que permitalhe desenvolver um projeto profissional ou projeto de vida, também denominado nas Casas Familiares Rurais (CRFs) de Projeto Profissional de Vida do Jovem (PPVJ). Nessa perspectiva, o estudante precisa apreender os conhecimentos científicos e técnicos, associando-os à sua vida familiar, tendo como metodologia pedagógica a alternância.

Assim, a Pedagogia da Alternância pensa a educação de forma integral e procura preparar o jovem para atuar na sociedade. A educação integral torna-se um desafio não só para a própria metodologia, mas para as ações educativas do campo. Conforme Pezarico, “[...] é por meio desta relação que se vislumbra no bojo da Pedagogia da Alternância possibilidades para o desenvolvimento do meio em diversas dimensões, principalmente, por consistir num processo de formação que abarca a família e sujeitos da comunidade local” (2014, p.78).

Dessa maneira, a Pedagogia da Alternância proporciona ao jovem um processo de construção de sua própria autonomia.

Isso é possível através dos movimentos de formação por alternância, sobretudo por alguns aspectos: a) A elaboração e a aplicação de ferramentas pedagógicas e dispositivos pedagógicos que dêem sentido à ação educativa; b) A formação inicial e contínua dos monitores; c) A investigação, com finalidade de vincular a ciência e o espírito científico; d) A informação e a consolidação institucional; e) A defesa da especificidade pedagógica organizadora, ou seja, de que se detenha autonomia para as instâncias políticas administrativas. Neste sentido, verifica-se que a autonomia como amálgama da práxis pedagógica inerente à Pedagogia da Alternância possui raízes que dialogam permanentemente com os fatores que estão no cerne de sua origem, quais sejam, as demandas, os limites e possibilidades que compunham os movimentos camponeses que a originaram (PEZARICO, 2014, p. 78).

Begnami (2005) afirma que o projeto educativo de uma escola por meio da Pedagogia da Alternância deixa para trás uma pedagogia plana para ingressar numa pedagogia do espaço, desenvolvido em dois tempos, um movimento que oferece alguns benefícios no âmbito escolar, familiar e comunitário, como segue:

\section{POLÊM!CA $\mid$ LABORE}


As vantagens no âmbito escolar são:

- Espaço privilegiado de socialização, do aprender a ser, a conviver e a trabalhar em equipe;

- Presença de uma equipe de educadores/as que acompanham de forma personalizada, estabelecendo um clima de amizade e respeito mútuo;

- Um amplo espaço de formação que motiva a construção de um projeto profissional;

- Um currículo que parte da realidade e valoriza a cultura do estudante e sua comunidade;

- Um conjunto de atividades informais complementares que estimulam a criatividade, a autonomia, a espontaneidade e a auto-estima;

- A família que se envolve na vida da escola e da formação do filho.

As vantagens no âmbito familiar e comunitário são:

- A alternância permite a manutenção dos vínculos do jovem com sua família e comunidade;

- O estudante não é distanciado de seus parentes, amigos e grupos da comunidade;

- Ligações com as raízes, valorização da vida e priorização das experiências como meio de aprendizagem e lugar de intervenções;

- Incentivo a práticas sociais, motivando os jovens a participar e a engajar-se em um grupo social concreto. (BEGNAMI, 2005, p. 41).

Nesse processo dinâmico, os papéis mudam se comparados à forma como acontece nas escolas "costumeiras". O jovem, agora "alternante", não é mais um aluno na escola, mas um autor em seu próprio território a partir de seu contexto de vida. "Sua família é convidada a participar ativamente de sua educação, de sua formação, acima de tudo porque é jovem" (GIMONET, 2007, p. 20). Os valores, portanto, que aqui se impõem, são fundamentalmente o da dimensão comunitária, forma de relação da experiência do homem medieval e que, aqui, ganha contornos significativos como forma de se contrapor ao modelo de sociabilidade marcado pelo individualismo.

O processo de ensino e aprendizagem torna-se possível, segundo Begnami (2005), Queiroz et al (2006) e Gimonet (2007), devido ao conjunto de instrumentos pedagógicos. Esses, permitem ao jovem agricultor perceber o que possui em sua propriedade e sua capacidade perante os aspectos econômicos, sociais, políticos, ecológicos na perspectiva de novas ações para o desenvolvimento sustentável. A organização do Plano de Formação articula esses instrumentos pedagógicos e serve de conexão entre a escola, a família e a comunidade, facilitando o aprendizado do jovem. Desta forma, apresenta-se na sequência algumas das ferramentas e/ou instrumentos pedagógicos.

O Caderno de Vida ou Caderno da Realidade permite um elo entre a família e a escola. Nele são feitas anotações com dúvidas ou experiências vivenciadas na propriedade

\section{POLÊM!CA $\mid$ LABORE}

Polêmica - Revista Eletrônica da Uerj - Rua São Francisco Xavier, 524, $1^{\circ}$ andar

bloco D, sl.1001 • Tels.: +55 21 2334-4088 / 4087 • http://www.e-publicacoes.uerj.br/index.php/polemica/index

http://www.labore.uerj.br • laboreuerj@yahoo.com.br 
para reflexão na escola e vice-versa. Segundo Gimonet (2007, p. 38): "Cada meio de vida representa um suporte de atividades e experiências de várias naturezas, uma reserva de saberes múltiplos. Cada meio de vida destes é portador de uma cultura local que se faz presente nos fatos e nos gestos, na linguagem e nos comportamentos".

A Colocação em Comum, um diálogo que ocorre entre os jovens e os professores/monitores, permite ao professor/monitor saber o que ocorreu entre o espaço de formação, a escola e a sua propriedade, ou seja, tem a função de articulação dos dois espaçostempos da alternância. Além disso, permite aos jovens alternantes um diálogo do individual ao coletivo. Conforme Gimonet (2007, p. 42): “O valor da colocação em comum depende então, em grande parte, dos estudos realizados pelos alternantes. Seu conteúdo e sua riqueza orientam e determinam o que precisa ser colocado em comum a fim de garantir um acréscimo e um enriquecimento dos estudos pessoais".

As Visitas de Estudos ou Intervenções podem ocorrer fora da escola ou a partir de uma intervenção dentro da escola. Elas têm por finalidade propor aos jovens descobertas de empreendimentos, realizações, de serviços, de lugares, dentre outros. Essas visitas acontecem a partir de um tema proposto na alternância. "Durante a visita ou intervenção prevalecem as seguintes atitudes que são fundamentalmente valores éticos: interesse, escuta, atenção, respeito, mas também o questionamento e o levantamento das informações essenciais que foram captadas" (GIMONET, 2007, p. 48).

O Plano de Estudo constitui uma ferramenta que possibilita o professor/monitor averiguar os conhecimentos prévios dos jovens em relação a determinado tema proposto. Para Gimonet (2007), o Plano de Estudo é considerado um instrumento-chefe da pedagogia. E é utilizado como meio de exploração, de expressões e de formalização dos componentes de uma das entidades de formação. $\mathrm{O}$ instrumento permite que o jovem descreva sua realidade e, além disso, busque informações por meio de questionamentos e observações. Também possibilita aos jovens, conjuntamente com seus familiares, buscarem conhecimentos na escola que lhes sirvam de aporte para questionamentos de suas realidades de vida e de suas condições de existência.

O Plano de Formação, considerado uma das ferramentas mais importantes da Pedagogia da Alternância, tem a função de organizar, agenciar e estruturar o percurso formativo.

\section{POLÊM!CA $\mid$ LABORE}


Ele confere o eixo norteador, uma espécie de coluna vertebral do processo. Ele integra, dá coerência às finalidades do projeto educativo, enuncia os objetivos e as etapas, articula os tempos, as atividades [...]. Em outros termos, pode-se defini-lo como 'plano de vôo' do percurso formativo e educativo. (GIMONET, 2007, p.70).

A construção do Plano de Formação é realizada a partir dos professores/monitores, através de uma pesquisa participativa em que os jovens e suas famílias são convidados a participar. Tem por função coletar informações sobre a propriedade dos jovens, sua comunidade, ou seja, o meio onde vivem. Após a coleta de informações são criados os temas de estudo. Esses temas de estudo passam a constituir os "temas geradores". Eles são considerados o fio condutor para as semanas de alternância dos jovens campesinos no espaço escolar.

Para Freire (2005, p. 114), “o Tema Gerador não pode se encontrar nos homens isolados da realidade, nem tampouco na realidade separados dos homens. Só pode ser compreendido nas relações homens-mundo".

O Plano de Formação articula todas as ferramentas que compõem a Pedagogia da Alternância. Assim, é, essencialmente, um meio de educação, de formação e conhecimento de cada jovem. Por isso, esse instrumento constitui-se em um processo fundamental de construção de conhecimento e, portanto, de valores fundamentais à existência, pois, o que está em jogo, é uma construção partilhada, uma construção que se dá na lógica da comunhão. Portanto, o Plano de Formação é portador de uma teleologia, onde, todos os pontos articulados entre si, apontam para um quadro de valores, onde o que está em jogo é o ir mais para além do individualismo. Daí, sua dimensão comunitária. Tal dimensão é característica do homem no horizonte da medievalidade, herança esta, portanto, dos valores advindos da tradição judaico-cristã - que também se encontram no processo de formação da tradição islâmica - e que se manterá de maneira perene e em tensão com outras tradições de pensamentos formulados no horizonte da tradição da modernidade.

Os jovens campesinos engajados pela dinâmica proporcionada pela Pedagogia da Alternância, para concluírem seu percurso no Ensino Médio, realizam uma experiência de vivência fora de sua propriedade, chamada de Projeto Profissional ou Projeto de Vida, que pode receber outras nomenclaturas, mantendo a finalidade de um trabalho de conclusão de curso. O projeto é desenvolvido no $3^{\circ}$ ano por meio de um estágio supervisionado, no qual o

\section{POLÊM!CA $\mid$ LABORE}


jovem campesino escolhe uma atividade econômica que seja uma possível fonte de renda para seu futuro, podendo optar entre desenvolver em uma propriedade agrícola ou uma empresa não agrícola, com o objetivo de promover o desenvolvimento sócio-profissional do jovem camponês.

É nesse contexto que a Pedagogia da Alternância pode responder a desafios importantes na educação, pois, enquanto educação integral, porta possibilidades e potencialidades para a formulação de um modelo de economia, já que, além de superar dialeticamente o modelo de educação dominante e vigente, como visto, também passa a ser o de superar crítica e dialeticamente um modelo econômico concentrador e excludente, nada solidário, afirmador de uma visão mais individualista que comunitária; a marca, o traço essencial e fundamental da Maison Familiale Rurale, mais que uma visão individualista, se constitui em uma visão comunitária, portanto, de comunhão dos bens, tanto simbólicos quanto dos materiais fundamentais à produção e à reprodução da vida, da existência, da cultura.

\section{A Pedagogia da Alternância e a Economia da Comunhão: um horizonte para o desenvolvimento de um modelo de economia}

Celso Furtado, em o Capitalismo Global, diz:

[...] não podemos escapar à evidência de que a civilização iniciada pela Revolução
Industrial aponta de forma inexorável para grandes calamidades. Ela concentra
riqueza em benefício de uma minoria cujo estilo de vida requer dispêndio crescente
de recursos não-renováveis e que somente se mantém porque a grande maioria da
humanidade se submete a diversas formas de penúria, inclusive a fome. Uma
minoria dispõe dos recursos não-renováveis do planeta sem preocupar-se com as
consequêencias para as gerações futuras do desperdício que ela hoje realiza.
(FURTADO, 1998, 63-64).

O modelo concentrador que o Capitalismo, desde a Revolução Industrial, principalmente, tomou forma é um modelo da não comunhão com o outro e com a própria natureza. Em relação ao outro, ainda um contingente enorme da espécie humana se mantém na penúria e na fome e, em relação à natureza, os recursos não-renováveis cada vez mais vão ficando comprometidos, alterando, inclusive toda dimensão climática do planeta. Moacir Gadotti em a Pedagogia da Terra diz que o "Capitalismo aumentou mais a capacidade de destruição da humanidade do que o seu bem-estar e a sua prosperidade”. No entanto, também não poupa críticas ao Socialismo quando diz que: “As realizações concretas do socialismo

\section{POLÊM!CA $\mid$ LABORE}

Polêmica - Revista Eletrônica da Uerj - Rua São Francisco Xavier, 524, $1^{\circ}$ andar

bloco D, sl.1001 • Tels.: +55 21 2334-4088 / 4087 • http://www.e-publicacoes.uerj.br/index.php/polemica/index http://www.labore.uerj.br • laboreuerj@yahoo.com.br 
seguiram na mesma esteira destrutiva, colocando em risco não apenas a vida do ser humano mas de todas as formas de vida existentes sobre a Terra" (GADOTTI, 2000, p. 31). Desta forma, pode-se dizer que, empregando uma figura apresentada por Luigino Bruni em A Ferida do Outro: Economia e Relações Humanas, que o "outro é uma ferida e, portanto, algo a se evitar, se pudermos" (BRUNI, 2010, p. 17). Portanto, a modernidade ocidental formulou um modelo econômico e uma ciência econômica sem gratuidade, porque não da comunhão, não da partilha, não da alegria, não da generosidade, não da compaixão. O outro e a natureza também enquanto um outro são realidades feridas, portanto ${ }^{4}$.

O tema da economia se impõe, então, a esta reflexão e o que se quer perseguir é que a Pedagogia da Alternância desde sua constituição histórica, epistemológica e lógica está em consonância com um modelo de economia que se está aqui reconhecendo como a Economia de Comunhão ${ }^{5}$.

Assim, se é verdade, que a Pedagogia da Alternância apropriada e subsumida pelo MST se aproxima de um modelo de economia que é a Economia Solidária, não é menos verdade que estes dois modelos de economia - a Economia Solidária e a Economia de Comunhão - se excluem mutuamente. Em que pese as origens distintas de ambos os modelos, pois, se a Economia de Comunhão se fundamenta na tradição aristotélica, na tradição patrísco-escolástica, na tradição da economia civil formulada por Antonio Genovesi, filósofo da segunda metade do século XVIII, e na tradição do pensamento social da igreja católica (BRUNI, 2005; 2010; BRUNI e ZAMAGNI, 2010), a Economia Solidária, por sua vez, se fundamenta em um processo da evolução do cooperativismo que tem seu início no contexto

\footnotetext{
${ }^{4}$ Oscar Maradiaga ao discutir o tema da ética e do desenvolvimento no contexto do mundo que segue o curso da globalização assim diz: “Às vezes, os números ajudam a entender a época em que vivemos. Atualmente, há no mundo 1.226 bilionários, o maior número jamais registrado até agora. Há, ao mesmo tempo, 925 milhões de pessoas que passam fome. No ano passado, só nos Estados Unidos foram gastos 50 bilhões de dólares com alimentos para animais domésticos, a mesma quantia prometida pelo G-8 em 2005 aos países mais pobres, promessa esta que ainda não foi cumprida. Na China, a General Motors vende um automóvel a cada 12 segundos, ao passo que a cada 12 segundos uma criança morre de fome no mundo. A globalização tem muitas contradições, é complexa e ambígua. O modo como a gerimos é a chave do nosso trabalho e da nossa responsabilidade pelo futuro" (MARADIAGA, 2015, p. 17.).

${ }^{5}$ Vale reconhecer que o debate sobre a Economia no Campo da Educação, principalmente na América Latina Caribenha, faz-se fundamental e necessário, principalmente, uma outra economia que não a Economia Capitalista. Na América Latina Caribenha e principalmente nos países emergentes como a Índia, por exemplo, há já uma vasta discussão sobre tal questão. Assim, por exemplo, Amartya Sen (2011) e Muhammad Yunus (SPIEGEL, 2010), configuram-se como importantes pensadores que colocam em relevo o debate da Economia com a Justiça, com os Pobres etc. Na América Latina Caribenha, estabelecendo relações da Economia com a Teologia, Hugo Assmann (1997) e Franz J. Hinkelammert são passagens e expoentes obrigatórios, pois, ambos instauram um pensamento não eurocêntrico, desde as maiorias vítimas do Sistema Capitalista.
}

\section{POLÊM!CA $\mid$ LABORE}

Polêmica - Revista Eletrônica da Uerj - Rua São Francisco Xavier, 524, $1^{\circ}$ andar

bloco D, sl.1001 • Tels.: +55 21 2334-4088 / 4087 • http://www.e-publicacoes.uerj.br/index.php/polemica/index http://www.labore.uerj.br • laboreuerj@yahoo.com.br 
da Revolução Industrial, desenvolvido por exemplo pelos formuladores do socialismo utópico como Owen, Fourier, Saint-Simon (SINGER, 2002) ${ }^{6}$.

Sob o ponto de vista da constituição epistemológica e lógica a Economia de Comunhão está para a Pedagogia da Alternância, uma vez que ambas as proposições encontram sua coerência no campo do pensamento social católico. Se o Padre Abbé Granereau, em 1935, na França, formula nas sendas do pensamento social católico a Pedagogia da Alternância a partir de sua preocupação com a juventude que estava abandonada no campo, Chiara Lubich, agora, no Brasil, formula, nas sendas também da tradição do pensamento social católico a Economia de Comunhão ${ }^{7}$. Em 1991, quando de sua chegada ao Brasil, em São Paulo, fica impactada com as desigualdades sociais marcadas pela opulência de arranha-céus e pela extensão das favelas. E seu pensamento que emerge de uma espiritualidade e que tem desdobramentos na Educação, na Saúde, na Política, na Cultura, na Filosofia, na Teologia, no Direito, na Arte, ao tocante à questão econômica dirá que "o centro de todo o sistema produtivo não é o homem, mas a própria produção. O que conta são os bens, e não o homem e seu trabalho" (LUBICH, 2003, p. 341). Tanto Padre Abbé Granereau na França, quanto Chiara Lubich no Brasil, em espaços e tempos distintos, mas, no mesmo marco da economia capitalista, estão a formular duas possibilidades que se complemetam, pois, tanto a Pedagogia da Alternância quanto a Economia de Comunhão (EdC) estão a

\footnotetext{
${ }^{6}$ Um debate foi instaurado sobre três tendências de pensamento de Economia e de Educação do Campo no II Seminário de Extensão sobre Pedagogia da Alternância - UTFPR - Campus Pato Branco - Paraná. "Se no Continente Europeu as três perspectivas epistemológicas, com suas respectivas metodologias, lógicas, éticas e estéticas estão em tensão reagindo ao Capitalismo e ao Liberalismo dos séculos XIX e XX, aqui na América Latina Caribenha, se constituirão também, em analíticas epistemológicas de leitura da realidade latinoamericana-caribenha marcada por uma profunda injustiça estrutural. Assim, se a Pedagogia da Alternância está em relação direta ao Pensamento Social Católico e à Economia de Comunhão, pode-se dizer que, também, podese buscar tanto no Socialismo Libertário quanto no Socialismo Marxista, outras duas infra-estruturas epistemológicas à Pedagogia da Alternância - bem como às outras Pedagogias da Terra -, justamente porque, a maneira como se traduz estas estruturas teóricas em solo latino-americano-caribenho tem a ver com o modo e o jeito como estas idéias são recepcionadas a partir dos problemas existentes no Continente, principalmente, em um continente marcado pela imensa pobreza das gentes que vivem em um Capitalismo dependente e periférico. Desta maneira, se na Europa da década de 30 do século passado, a Pedagogia da Alternância está em relação direta ao Pensamento Social Católico, no Continente Latino Americano Caribenho ela está para as três perspectivas analíticas epistemológicas: a do Socialismo Cristão, a do Socialismo Libertário e a do Socialismo Marxista, porque três estruturas analíticas críticas ao Capitalismo e ao Liberalismo" (BORTOLETO, 2014).

${ }^{7}$ A Economia de Comunhão (EdC): é um movimento internacional que envolve empresários, associações, instituições econômicas, bem como trabalhadores, dirigentes, consumidores, poupadores, estudiosos, operadores econômicos, pobres, cidadãos, famílias. Quem adere, em qualquer nível, à EdC se compromete em viver os valores e a 'cultura da comunhão', ou seja, a 'cultura do dar' e da reciprocidade, a fim de que ela penetre sempre mais no mundo da economia e em todos os âmbitos. (LUBICH, 2003).
}

\section{POLÊM!CA $\mid$ LABORE}

Polêmica - Revista Eletrônica da Uerj - Rua São Francisco Xavier, 524, $1^{\circ}$ andar

bloco D, sl.1001 • Tels.: +55 21 2334-4088 / 4087 • http://www.e-publicacoes.uerj.br/index.php/polemica/index http://www.labore.uerj.br • laboreuerj@yahoo.com.br 
apontar elementos críticos à uma sociedade constituída na opulência de alguns e na miserabilidade de muitos, portanto, um modelo de sociedade e de economia sem gratuidade.

A Economia Solidária também emerge de uma realidade que se constitui nos marcos do Capitalismo. Como afirma Singer, "a economia solidária nasceu pouco depois do capitalismo industrial, como reação ao espantoso empobrecimento dos artesãos provocado pela difusão das máquinas e da organização fabril da produção" (2002, p. 24). Assim, frente à competição na economia, a solidariedade se impõe como valor imperativo para a Economia Solidária. Na Economia de Comunhão a gratuidade e a cultura do dar se impõe também como imperativos. Portanto, dois modelos de economias que, emergindo das feridas produzidas pelo Capitalismo, apontam a Solidariedade e a Comunhão, como forma de crítica e de superação do Capitalismo enquanto modelo de economia. Em suas diferenças lógicas e epistemológicas, portanto, os dois modelos estão a abraçar o outro e a natureza.

Ora, a comunhão e a solidariedade estão em relação direta com a Pedagogia da Alternância, isto porque a experiência da Maison Familiale Rurale - que ganha extensão hoje em uma parcela significativa do planeta - não pode se fechar à formulação de um horizonte econômico enquanto pensar a própria casa onde todos - seres vivos orgânicos e inorgânicos mais que em competitividade se encontra em solidariedade e em comunitariedade. A visão integral de pessoa e de realidade que a Pedagogia da Alternância vem formulando desde seus primórdios na França e que ganha lugar em tantas partes, principalmente na América Latina Caribenha e, de modo especial no Brasil, que já está em diálogo com a Economia Solidária, pode, pelas razões já apresentadas, estar em diálogo com a Economia de Comunhão. Se estes dois modelos têm diferenças epistemológicas e lógicas, não os têm em sua constituição ontológica, pois a origem destes dois modelos econômicos se encontram em Atos dos Apóstolos 2:45, de autoria da comunidade lucana: "vendiam suas propriedades e bens, e dividiam-nos entre todos, segundo as necessidades de cada um" (BIBLÍA DE JERUSALÉM, 2004).

Tal premissa bíblica está na base da formulação de perspectivas de pensamentos sociais e antropológicos presentes nas três direções de socialismos, quais sejam, o Socialismo Cristão, o Socialismo Libertário $^{8}$ e o Socialismo Marxista. Três abordagens que no século XIX põem em questão o tema da necessidade, elemento fundamental e núcleo essencial do

${ }^{8}$ Para a compreensão do Socialismo Libertário, dentre as várias orientações, vale referenciar pelo menos: Fourier (1995), Proudhon (2003, 1997), Reclus (2015, 1985), Russ (1991).

\section{POLÊM!CA $\mid$ LABORE}


debate econômico. No entanto, o referido tema da necessidade na perspectiva da Economia da Comunhão não pode ser pensado fora da gratuidade. Economia e gratuidade se imbricam enquanto pólos necessários, portanto. Este tema também atravessa a perspectiva libertária e marxista. No horizonte do homem moderno a gratuidade foi restringida ao âmbito da esfera privada e não à esfera pública, tal como aponta Luigino Bruni: “A cultura da modernidade tentou relegar a gratuidade à esfera privada, banindo-a completamente da esfera pública. Expulsou-a, sobretudo, da esfera econômica: para a economia bastam os contratos, os incentivos, as regras claras e os juros" (2005, p. 55). Assim, pode-se formular a seguinte fórmula: $\mathrm{e}=\mathrm{n}+\mathrm{g}$, ou seja, a Economia passa necessariamente pela necessidade e pela gratuidade. Prossegue Bruni: "se a economia fosse concebida e praticada como gratuidade, então aconteceria (realmente) que, ao produzirmos, trabalharmos, nos cansarmos e sofrermos, não estaríamos somente produzindo, cansando-nos e sofrendo: estaríamos suscitando um novo humanismo" (2005, p. 55).

\section{Referências}

ARroyo, M. G.; CALDART, R. S. MOLINA, M. C. (org.). Por uma educação do campo. Petrópolis: Vozes, 2011. 214 p.

ASSMANN, H. La idolatria del mercado. 1. ed. San José, C.R.: DEI, 1997. 269 p.

BEGNAMI, J. B. Pedagogia da alternância como sistema educativo. Revista de Formação por Alternância, Brasília, 1(2): 24-47, 2005.

BÍBLIA DE JERUSALÉM. Atos dos Apóstolos. Português. Nova Edição. 3. imp. São Paulo: Paulus, 2004. $2206 p$.

BORTOLETO, E. J. Em torno de três epistemologias e de três modelos econômicos às pedagogias da terra: o pensamento libertário e a economia comunal, o pensamento marxista e a economia solidária e, o pensamento social da igreja católica e a economia de comunhão. II Seminário de Extensão sobre Pedagogia da Alternância UTFPR - Campus Pato Branco - Paraná. Roda de Diálogo: Pedagogias da Terra e suas Epistemologias. 2014.

BRUNI, L. Comunhão e as novas palavras em economia. Vargem Grande Paulista: Cidade Nova, 2005. 183 p.

A ferida do outro: economia e relações humanas. São Paulo: Cidade Nova, 2010. 213 p.

BRUNI, L.; ZAMAGNI, S. Economia civil: eficiência, equidade, felicidade pública. Vargem Grande Paulista: Cidade Nova, 2010. 288 p.

CALDART, R. S. Dicionário da educação do campo. São Paulo: Expressão, 2012. 788 p.

FERNANDES, B. M.; CERIOLI. P. R.; CALDART, R. S. Primeira conferência nacional por uma educação do campo. In: ARROYO. M. G.; CALDART, R. S. MOLINA, M. C. (org). Por uma educação do campo. Petrópolis: Vozes, 2011.

\section{POLÊM!CA $\mid$ LABORE}


FENANDES, B. M. Territórios da educação do campo. In: ANTUNES-ROCHA, M. I.; MARTINS, M. de F. A.; MARTINS, A. A. (Orgs.). Territórios educativos na educação do campo: escola, comunidade e movimentos sociais. Belo Horizonte: Autêntica, 2012.

FREIRE, P. Pedagogia do oprimido. $41^{\mathrm{a}}$ ed. São Paulo: Paz e Terra, 2005. 213 p.

FOURIER, C. EI Nuevo mundo industrial y societario. México: Fondo de Cultura Económica, 1995. 511 p. FURTADO, C. O capitalismo global. $2^{\text {a }}$ ed. São Paulo: Paz e Terra, 1998. 83 p.

GADOTTI, Moacir. Pedagogia da terra. São Paulo: Editora Fundação Petrópolis Ltda, 2000. 217 p.

GHEDIN, E. Educação do campo: epistemologia e práticas. São Paulo: Cortez, 2012. 448 p.

GIMONET, J. C. Praticar e compreender a pedagogia da alternância dos CEFFAS. Petrópolis, RJ: Vozes, 2007. $167 \mathrm{p}$.

LÖWY, M. (Org.). O Marxismo na América Latina: uma ontologia de 1909 aos dias atuais. São Paulo: Fundação Perseu Abramo, 1999. 563 p.

LUBICH, C. Ideal e luz: pensamento, espiritualidade, mundo unido. São Paulo: Cidade Nova, 2003. 454 p.

MARADIAGA, O. Sem ética não há desenvolvimento. Petrópolis-RJ: Vozes, 2015. 71 p.

NOSELLA, P. Educação no campo: origens da pedagogia da alternância no Brasil. Vitória: EDUFES, 2012. $288 \mathrm{p}$.

PEZARICO, G. A casa, a terra e o mar: os objetos e os espaços no contexto da Pedagogia da Alternância. Curitiba, PR. Tese (Doutorado em Tecnologia) - Universidade Tecnológica Federal do Paraná. Programa de Pós-Graduação em Tecnologia, 204 p. 2014.

PROUDHON P.-J. Sistema das contradições econômicas ou filosofia da miséria. São Paulo: Ícone, 2003. 438 p.

A propriedade é um roubo e outros escritos anarquistas. Porto Alegre: L\&PM, 1997. 172 p.

QUEIROZ, J. B. P.; SILVA, V. C.; PACHECO, Z. Pedagogia da alternância: construindo a educação do campo. Goiânia: UCG, 2006. 155 p.

\section{POLÊM!CA $\mid$ LABORE}


RECLUS, É. Do Sentimento da natureza nas sociedades modernas e outros escritos. São Paulo: Intermezzo Edusp, 2015. $461 \mathrm{p}$.

Élisée Reclus - Geografia. São Paulo: Editora Ática, 1985. 200 p.

RUSS, J. O socialismo utópico. São Paulo: Martins Fontes, 1991. 258 p.

SEN, A. A ideia de justiça. São Paulo: Companhia das Letras, 2011. 492 p.

SINGER, P. Introdução à economia solidária. São Paulo: Fundação Perseu Abramo, 2002. 127 p.

SPIEGEL, P. Muhammad Yunus, o banqueiro dos pobres: sua vida, visão e atuação. Vargem Grande Paulista, SP: Cidade Nova, 2010. 149 p.

Recebido em: 30/05/2016.

Aceito em: 24/02/2017.

\section{POLÊM!CA $\mid$ LABORE}

